\title{
“LENTES” HERMENÊUTICAS DE MEISTER ECKHART
}

\author{
Hermeneutic "Lenses" of Meister Eckhart
}

\author{
Josué Soares Flores*
}

\section{RESUMO}

O artigo a seguir pretende apresentar Meister Eckhart, teólogo místico alemão do século XIII, da Ordem dos Pregadores (Dominicanos) como referência na hermenêutica bíblica a partir da Teologia Negativa e Ascética, dialogando com a Escolástica, com a literatura Mística da Tradição Cristã e a literatura Hermética e Sapiencial. Fundamos nossa análise sobre os textos dos Sermões Alemães, obra de Eckhart, em que ele faz comentários bíblicos, utilizando os métodos exegéticos medievais, sempre destacando os elementos conceituais de sua Teologia Mística, permitindo criativamente uma interpretação ímpar que influenciará as demais gerações de místicos(as) nos séculos seguintes. Eckhart irá responsavelmente transcender tanto os limites dogmáticos do magistério, quanto o método exegético e as fronteiras da Escolástica, sendo por isso, incompreendido e condenado como anátema. Eckhart é aqui apresentado para os que suspeitam estar a Teologia demasiadamente presa ao método, ao dogma e à razão para a superação criativa e responsável em direção à transcendência.

Palavras-chave: Meister Eckhart. Hermenêutica. Teologia Ascética. Sermões. Exegese Medieval. Teologia Apofática.

* Sacerdote Anglicano, membro da Junta Nacional de Educação Teológica da Igreja Episcopal Anglicana do Brasil; coordenador da Comissão Diocesana de Educação Cristã e Teologia da Diocese Anglicana de Curitiba e do Núcleo de Estudos Anglicanos de Curitiba; Bacharel em Ciências Sociais pela Universidade Estadual de Londrina e em Teologia pela Faculdade Teológica Sul-Americana e Seminário Teológico Revdo. Antônio de Godoy Sobrinho; Mestre em Teologia pela Pontifícia Universidade Católica do Rio Grande do Sul; Doutorando no Programa de Pós-Graduação em Teologia da Pontifícia Universidade Católica do Paraná(Campus Curitiba).E-mail:<josuka.soares@gmail.com>.

\begin{tabular}{|l|l|l|l|l|l|}
\hline Teocomunicação & Porto Alegre & v. 44 & n. 3 & p. 342-353 & set.-dez. 2014 \\
\hline
\end{tabular}




\begin{abstract}
The following article intends to present Meister Eckhart, German mystical theologian of the thirteenth century, the Order of Preachers (Dominicans) as a reference in biblical hermeneutics from Negative Theology and Ascetic, dialoguing with Scholastic, with Mystical Christian Tradition and Literature Hermetic and the Wisdom literature. We founded our analysis of the texts of sermons Germans work of Eckhart he makes biblical commentaries using medieval exegetical methods stressing the conceptual elements of his Mystical Theology, creatively enabling a unique interpretation that will influence other generations of mystics in the centuries following. Eckhart will responsibly transcend both the dogmatic limits of teaching, as the exegetical method and the boundaries of scholarship, and so misunderstood and condemned anathema. Eckhart is presented here for those suspected of being too attached to the Theology method, the dogma and the reason for the creative and responsible towards overcoming transcendence.
\end{abstract}

Keywords: Meister Eckhart. Hermeneutical. Ascetical Theology. Sermons. Medieval exegesis. Apophatic Theology.

\title{
Breve biografia
}

Meister Eckhart viveu num período bastante intenso e efervescente da Igreja e da sociedade europeia. Eckhart nasceu em $1260 \mathrm{em}$ Hochheim (Turíngia) e ainda cedo ingressou na Ordem Dominicana que havia recém-surgido (1216). Ele presencia as catástrofes da peste ngra e o Cativeiro Babilônico do Papado em Avignon. Aos 17 anos, estuda Artes em Paris onde provavelmente tenha sido discípulo de João Duns Scotus. Aos 20, anos estuda Teologia em Colônia onde mais tarde será também Diretor. Em Colônia foi discípulo de S. Alberto Magno. Após sua formação, irá lecionar Teologia em Paris, projetando-se como grande mestre, fato que irá encaminhá-lo para um papel de liderança na Ordem Dominicana, chegando a ser Provincial da Saxônia e, depois, da Província Teutônica e vigário-geral (substituto do superior-geral dos Dominicanos). Aos 43 anos, doutora-se em Teologia e é nomeado ordinário como exegeta dos textos bíblico. Nesse tempo passa a ser chamado Meister (Mestre). Aos 51 anos, Eckhart deixa Paris por conta das rivalidades teológicas entre franciscanos e dominicanos, fato que tardiamente irá prejudicá-lo, sendo condenado por heresias. Em 1326, o arcebispo franciscano de Colônia inicia um processo inquisitorial contra Eckhart. No ano seguinte, Eckhart irá publicar uma profissão de fé pela ortodoxia. Ainda assim, em 1329 o Papa João XXII, na Constituição 
In agro domínico, irá condenar Eckhart por 17 heresias entre outros ensinos 'temerários', bem como seus livros que contivessem estes ensinos. Para seu menor desgosto, Eckhart faleceu em 1328 em Avignon. Eckhart terá grandes discípulos como João Tauler e Henrique Suso e sua obra irá influenciar toda geração de místicos e místicas posteriores. Seu trabalho de acompanhamento pastoral dos conventos femininos irá colocá-lo em contato direto com o povo, o que o faz pregar em língua alemã. Eckhart foi um teólogo e asceta incompreendido em seus dias e sua teologia mística tem sido revisitada. ${ }^{1}$ Vejamos abaixo algumas das lentes hermenêuticas usadas por Eckhart.

\section{Influência da Teologia Mística ou Ascética}

Os sentidos pulam para dentro dos pensamentos: só Deus e a alma conhecem sua altura e sua profundidade. (Sermão 71$)^{2}$

O fazer teológico dos(as) místicos(as) é antes uma iniciativa ontológica do próprio Deus, que é, na relação, conhecido não como objeto, como parte do método científico, mas como ente. "[...] Deus 'produz nas criaturas o amor que as faz tender para Ele; é Deus quem as atrai querendo que elas o desejem e possam amar o amor". ${ }^{3}$ A partir desse pressuposto, Evelyn Underhill destaca que existem duas formas de expressão que pertencem respectivamente aos místicos(as) do tipo transcendente-metafísico e íntimo-pessoal: e que suas fórmulas, se tomadas isoladamente, parecem contradizer a outra. $\mathrm{O}(\mathrm{a})$ místico(a) metafísico(a), para o(a) qual o Absoluto é impessoal e transcendente, descreve a sua realização final desse Absoluto como deificação, ou a transmutação total do eu em Deus. O(a) místico(a) para quem comunhão íntima e pessoal tem sido o modo em que ele(a) melhor apreende a Realidade, fala da consumação desta comunhão, a sua forma perfeita e permanente, como o casamento espiritual de sua alma com Deus. ${ }^{4}$

1 Ver mais em ECKHART, M. A Mística de Ser e de não Ter. Petrópolis: Vozes, Coord. Leonardo Boff, Série Espiritualidade 5, p. 23ss., 1983.

2 ECKHART, M. Sobre o desprendimento e outros textos. São Paulo: Martins Fontes, Trad. do Médio-Alemão de Alfred J. Keller, 1. ed., p. 45ss., 2004.

3 LOSSKY, V. La Teologia mística della Chiesa d'Oriente, 84. Apud: ZĂK, Lubomir. Trindade e Imagem - Aspectos da teologia mística de Vladimir Losskij. São Paulo: AveMaria, Márcio Luiz Fernandes (Org.), p. 101, 2012.

4 Cf. UNDERHILL, Evelyn. Mysticism - A study in the nature and development of Man's spiritual consciousness. New York: Meridian Books, p. 415, 1958. 
[...] quem recorre a nada para falar de Deus fala dele adequadamente. Quando a alma chega ao um e nele entra despojada totalmente de si mesma, então ela encontra Deus como que dentro de um nada. Como se fosse num sonho - mas um sonho lúcido - alguém se sentiu grávido de nada, como uma mulher fica grávida de um filho, e nesse nada nasceu Deus - foi ele o fruto do nada. Deus nasceu no nada. (Sermão 71) ${ }^{5}$

Os(As) grandes místicos(as), sobretudo anseiam por mostrarnos a verdade da deificação e não há nenhuma pretensão arrogante de identificação com Deus, mas como uma transfusão de si mesmo(a) para seu Eu: uma entrada em uma nova ordem de vida, alta e harmoniosa com a realidade que só pode ser chamada divina. Repetidas vezes nos asseguram que a personalidade não está perdida, mas mais real. Eckhart, longe de ser um místico de experiências extáticas, é um teólogo que busca um outro caminho para além da Escolástica, debruçando-se sob a influência de Pseudodionísio Areopagita, João Eriúgena, Gregório Palamas, Gregório de Nissa, entre outros. Sua teologia ascética é uma corrente subterrânea que convive paralelamente com a Escolástica, que tinha lugar privilegiado nos centros acadêmicos medievais. Essa relação, muitas vezes dialética e paradoxal, com a Escolástica, influenciada pela grande escola ascética da Tradição Cristã,, permitiu um olhar hermenêutico sui generis. Na citação abaixo, Eckhart toma de Dionísio seu diálogo com Timóteo e aponta para o sentido de sua teologia ascética e a influência que isso terá em sua hermenêutica bíblica:

[...] com espírito sem preocupação dos sentidos, tu deves ultrapassar a ti mesmo, transcender todas as tuas capacidades, superar o conhecimento e a razão, passar por cima da obra, modo e ser, lançando-te na escuridão serena do mistério, a fim de chegares a saber o Deus desconhecido que está acima de Deus. Deve-se retirar de todas as coisas. Deus resiste a agir por imagens. (Sermão 57) ${ }^{6}$

A citação acima permeia o exercício exegético uma vez que é o eixo da disciplina espiritual do teólogo místico. A transcendência do ser, da materialidade, do tempo e espaço, em direção ao lugar onde não há

\footnotetext{
ECKHART, M. Op. cit. p. 45ss., 2004.

6 ECKHART, M. O Livro da Divina Consolação e outros textos seletos. Petrópolis: Vozes, 2. ed., p. 180ss., 1991.
} 
imagem, onde não há dispositivo cognoscível para compreender, nesse abissal mistério é que Eckhart irá se debruçar em sua busca de sentido a partir da tradição bíblica.

\section{Teologia Negativa ou Apofática}

A Teologia Negativa ou Apofática concebe que não há recursos na linguagem e razão que sejam suficientes para a compreensão categórica e tipológica do objeto da Teologia, Deus. Por isso, toda a afirmação daquilo que é Deus é negada pelos teólogos apofáticos, pois tudo o que afirma ser Deus é insuficiente para esgotar, sendo por isso não Deus, pois deforma, delimita e cerceia o ente. Dado isso, a Teologia Negativa nega a toda a afirmação daquilo que Deus é, feita especialmente pelos dogmas, catecismos e ensino do magistério da Igreja.

O apofatismo consiste em negar aquilo que Deus não é. Primeiramente, nega-se tudo o que é criado, também a glória cósmica do céu estrelado, inclusive a luz do céu dos anjos, luz que se pode compreender com a razão. Em seguida, nega-se aquelas que são as mais sublimes propriedades: bem, amor, sabedoria. Enfim, nega-se, também, o próprio ser. Deus não é nada de tudo isso. Todavia - e é este o paradoxo cristão - Ele é aquele Deus ao qual eu chamo de 'Tu'?

A definição acima, do teólogo asceta russo Lossky, demonstra o claro objetivo do fazer teologia a partir da negação. Percebe-se a primeira negação enquanto um avançar para além da 'cortina de fumaça' espessa que envolve a compreensão de Deus sendo a materialidade chamada por ele daquilo tudo que é criado. Em seguida, o segundo passo da negação é o ir além da realidade metafísica a qual adjetiva o ente Deus, pois ele também não é e não pode ser confundido com aquilo que é criado, pois é incriado, e também não pode ser confundido com o que é incriado porque, segundo Lossky, surge a terceira negação, a do próprio ser. Mesmo o que é incriado está vinculado ontologicamente àquilo que é o ser, tendo potência e por isso finitude, e Deus não pode então ser, antes Ele não é. E Lossky chama-nos a atenção ao fato de que, embora ele não seja, ainda assim o tratamos pelo $t u$, estabelecendo uma

7 LOSSKY, V. Conoscere Dio. (Qiqajon, Magnano 1996), 14. Apud: ZĂK, Lubomir. Trindade e Imagem. p. 54, 2012. 
relação ontológica com aquilo que Eckhart irá chamar de Uno, causa de nossa busca por unidade num processo de aniquilação da alteridade em direção à deificação do ser. Segundo Lossky, "Deus não se apresenta como objeto, porque não se trata de conhecimento, mas sim, de união.

No irromper, contudo, onde me encontro vazio de minha própria vontade, vazio mesmo da Vontade de Deus e de todas as suas obras, sim, vazio de Deus ele mesmo, aí eu me encontro acima de todas as criaturas e não sou nem 'Deus' nem criatura; sou, antes, o que eu era, o que permanecerei agora e por todo o sempre. Aí eu recebo um impulso que me deverá conduzir acima de todos os anjos. Neste impulso recebo tamanha riqueza, que Deus com tudo aquilo que é como 'Deus' e com toda sua obra divina, não me pode ser suficiente; pois me é dado neste irromper, que eu e Deus sejamos Uno. Aí eu sou o que eu era. E aí nem acrescento nem diminuo. Pois sou aí uma causa imóvel, que move todas as coisas. Aqui Deus não encontra mais lugar algum no homem, pois o homem conquista, com esta pobreza, aquilo que ele era eternamente e permanecerá por todo o sempre. Aqui Deus é Uno com o espírito e isto é a mais autêntica pobreza que se possa encontrar. (Sermão 52$)^{8}$

A citação acima, do Sermão 52, baseia-se no versículo 3, capítulo 5 de S. Mateus. O tema da pobreza passa pela concepção de desprendimento. Desprendimento é um estar vazio, uma nadificação existencial, uma nudez total. É evidente que o sermão é um diálogo aberto com a tradição franciscana, e na apresentação de suas três pobrezas, Eckhart irá muito mais longe que a disciplina de nada ter, que em materialidade, era conhecida. Nesse aspecto, Eckhart irá aproximarse das filosofias hindu e budista. Assim, o fazer Teologia Negativa, também implica um elemento ativo do teólogo, a atitude kenótica que encontrará paradoxalmente a deificação, numa dialética ontológica.

Todas as criaturas trazem em si uma negação: uma nega ser a outra. $U m$ anjo diz que não é um outro (anjo). Deus, porém, tem um negar do negar: é Um e nega todo o outro, pois nada é fora de Deus. Todas as criaturas são em Deus e são a sua própria Divindade, e isto significa a plenitude, como eu disse acima. Ele é um Pai da Divindade inteira. [...] Deus é $U m$, Ele é um negar do negar. (Sermão 21) $)^{9}$

\footnotetext{
ECKHART, M. Op. cit. p. 189ss., 1991.

9 ECKHART, M. Op. cit. p. 165ss., 1983.
} 
A citação acima de M. Eckhart, baseada no versículo 6 do capítulo 4 da Epístola de São Paulo aos Efésios, 'Um Deus e Pai de todos, que é bendito acima de todos e por todos e em nós todos', é um exemplo da Teologia Negativa a qual norteia a hermenêutica eckartiana. No fundo desta interpretação, há um debate sério sobre a questão da alteridade e da natureza ontológica de Deus. Nesse contexto, a cosmologia, a soteriologia e a ética serão profundamente impactadas pela interpretação de Eckhart. O fato de que nada-é extra-Deus, mas tudo-está intraDeus deifica toda a criação, não num plano panteísta, mas num plano existencial-ontológico, ou seja, o meu esse (ser) é enquanto uma negação do outro, mas não enquanto uma negação de Deus, pois nada existe fora dEle.

"A teologia negativa é, portanto, um caminho de união com Deus, cuja natureza não é possível conhecer." (ZĂK, Lubomir, 2012, p. 55). A Teologia Apofática, nega que a Essência divina ou a Substância seja algo de tudo o que existe, isto é, nada que possa ser dito ou compreendido.

\section{Diálogo com o Hermetismo}

[...] tudo isso denota unidade em muitos. Esta, porém, não existe em lugar ou tempo algum, a não ser no intelecto, e mesmo ali ela não é, mas é pensada. Logo, ali onde o ser não é o pensar, nunca há igualdade. Mas só em Deus o ser é idêntico ao pensar. (Sermão 29) ${ }^{10}$

Para Eckhart não existe um percurso em direção a uma felicidade futura, mas um retorno à origem por meio do intellectus, porque Deus não é ser mas intellectus. Palavras como 'Paraíso' (aparecem apenas 07 vezes em sua obra) e 'Inferno' (03 vezes) não revelam um plano escatológico para o ser, mas um plano cosmológico, tendo mais relevância para a questão da alteridade o conceito e definição de Deus como intellectus. Eckhart não apenas torna o intelligere causa do esse (ser) na relação que intercorre entre o pensamento divino e a criação, mas afirma que o intelecto, em Deus, possui a função de estabelecer o fundamento do ser. Portanto, a pureza do ser compete a Deus em virtude do intelecto, que é superior ao ser. Ele, propriamente, é intelecto e não ser: uma reflexão ontológica, por conseguinte, é apenas preliminar, não apreendendo a essência divina. A superioridade do intelecto se dá em virtude de ele ser

${ }^{10}$ ECKHART, M. Op. cit. p. 160ss., 1983. 
princípio de todo ser e de estar acima do puro existir; o lugar dele é a alma, não como o ser que está nas coisas. Afirmando categoricamente que, em Deus, não há nem o ente nem o ser, Eckhart declara que a Criação está em condição de total dependência e de absoluta distinção com respeito ao Criador. Um elemento, porém, permanece inalterado quando o discurso verte sobre o ser, a saber, a referência à criação e a tentativa de compreender a relação desta com Deus: não há possibilidade de estabelecer uma comparação entre Deus e as criaturas, e a relação entre os dois só pode seguir a direção que vai dessas para Aquele.

Portanto, subir ao intelecto, e submeter-se a ele, é unir-se com Deus. Unir-se, ser um, é ser um com Deus. Pois Deus é um. Todo o ser além do intelecto, fora do intelecto, é criatura, é criável, é algo outro do que é Deus, não é Deus. Pois em Deus nada há de outro. (Sermão 29) $)^{11}$

Eckhart revela a dimensão profundamente intelectual da sua perspectiva: pelo fato de a alteridade ser excluída do puro ser divino, Deus é em si totalmente intelecto, porque, se fosse algo, seria composto e a simplicidade absoluta da sua unidade estaria comprometida. $\mathrm{O}$ homem, entretanto, é aspectum de Deus e Deus é respectum do homem: os dois formam uma única realidade, assim como o modelo e a imagem são unum, e não há inter-mediação que os separe, nem tempo, nem espaço, nem vontade, nem qualquer outra potência. Consequentemente, para o homem realizar sua vocação profunda de ser unum com Deus, tem que fazer retorno para Ele. Esse evento acontece toda vez que o homem, através de um despojamento radical, assume plenamente seu status de imago Dei, seu titulus de nobreza e seu ethos de justiça. "Por isso, um homem justo é única e exclusivamente aquele que reduziu a nada todas as coisas criadas e está em pé, voltado sem desvios, com olhar direto para a Palavra eterna, espelhando-se e refletindo-se na justiça" 12 .

Enquanto Tudo está n'O Todo, é também verdade que O Todo está em Tudo. Aquele que compreende realmente esta verdade alcançou o grande conhecimento. (Caibalion, cap. VII)

${ }_{11}$ ECKHART, M. Op. cit. p. 160ss., 1983.

12 ECKHART, M. Sermões Alemães 1. Bragança Paulista/Petrópolis: Ed. Universitária São Francisco/Vozes, Vl. 1 e 2, p. 124, 2006. 
Pois o intelecto é, propriamente, de Deus; Deus porém é um. Logo, o quanto cada qual tem de intelecto ou de capacidade intelectual, tanto tem de Deus, tanto do um e tanto do ser-um com Deus. Pois o Deus uno é intelecto, e o intelecto é o Deus uno. Por isso Deus nunca e nenhures é Deus, salvo no intelecto. [...] Portanto, subir ao intelecto, e submeter-se a ele, é unir-se com Deus. Unir-se, ser um, é ser um com Deus. Pois Deus é um. Todo o ser além do intelecto, fora do intelecto, é criatura, é criável, é algo outro do que é Deus, não é Deus. Pois em Deus nada há de outro. (Sermão 29) ${ }^{13}$

Acima, um pequeno dito sapiencial do Caibalion. Trismegisto é considerado o pai do Hermetismo, sendo autor do Corpus Hermeticum que influenciou toda a literatura ocidental. Há uma conexão entre os dois pensamentos, especialmente na concepção de Deus enquanto Uno, e no meio cognoscível de unir-se ao Uno. Eckhart constrói sua teologia ascética, não meramente na especulação filosófica, como era própria da escolástica, mas na tradição bíblica. O sermão 29 é todo dedicado a uma análise de Gálatas 3,16-22 e Deuteronômio 6,4; ou seja, os fundamentos teológicos de Meinster Eckhart não fugirão da exegese bíblica conforme os padrões medievais, entretanto, em sua hermenêutica, Eckhart irá longe em suas influências e encontra na literatura considerada pagã, um outro lugar teológico, e, embora não cite os nomes, em muitos lugares de sua obra, ele menciona o conhecimento dos mestres e místicos pagãos.

\section{Método exegético medieval}

Ao longo da Idade Média, a interpretação da Bíblia era monopólio do clero, especialmente aqueles sacerdotes ligados mais diretamente à cúpula da Igreja. Do ponto de vista hermenêutico, a leitura medieval possuía virtudes, em função de sua visão plural do sentido do texto; virtudes, porém, que ficaram subordinadas ao problema fundamental: a subordinação da significação textual ao dogma eclesiástico. Afirmavase, em geral, que o texto bíblico deve ser lido à luz de quatro dimensões de sentido: literal ou histórico, alegórico ou tipológico (com ênfase na cristologia), moral ou tropológico e anagógico ou místico (distinção que é atribuída a João Cassiano, autor do V século da era cristã):

${ }^{13}$ ECKHART, M. Op. cit. p. 160ss., 1983. 
Littera gesta docet (O sentido literal ensina os fatos).

Quid credas allegoria (O alegórico, o que crer).

Moralis quid agas (O moral, o que fazer).

Quo tendas anagogia (O anagógico, a direção a seguir). ${ }^{14}$

O sentido literal servia de base para os demais, especialmente para o alegórico, de modo que este não se tornasse excessivamente subjetivo. O sentido anagógico, que correspondia grosso modo à doutrina cristã, servia de critério para os demais na medida em que nenhuma interpretação da Bíblia poderia contradizer o ensino da Igreja. Assim, a Escritura passa a ser controlada pelo dogma e o texto é uma plataforma para o sentido, e não o lugar do sentido verdadeiro, apenas o locus da literalidade. Eckhart busca 'passar rasteira' no método e o rigor do magistério sobre ele, fazendo outras leituras possíveis, sem necessariamente negar o dogma, buscando sempre algo mais sobre o texto e ir além do magistério. Veja um trecho do sermão 28, sobre Marta e Maria, baseado em S. Lucas 10,38.

[...] a querida Marta e todos os amigos de Deus com ela estão 'com os seus cuidados', não porém 'dentro dos seus cuidados'. Nesse estado d'alma, a atuação no tempo é tão nobre quanto qualquer outra forma pela qual alguém se una a Deus, pois nos aproxima não menos de Deus que a forma mais elevada que nos possa ser concedida, com exceção unicamente da visão de Deus na sua própria natureza. Daí diz Ele (Cristo): 'Tu estás junto das coisas, e junto das tarefas', significando que com as forças inferiores da alma ela está, sem dúvida, exposta aos cuidados e às aflições, pois ela não era como que mimada pela gula espiritual. Ela estava junto das coisas, não nas coisas; ela estava... (Sermão 28) ${ }^{15}$

No início desse sermão, Eckhart faz uma apologia a Marta, subordinando sua ação a três razões a priori: sua idade e o modo de ela ser empenhada e dedicada ao extremo; a outra razão à sábia ponderação que orientava a atividade externa para o melhor que o amor possa ditar; e a terceira razão, a dignidade do hóspede. O sermão não se dá

\footnotetext{
${ }^{14}$ Poema de Nicolau de Lira, século XIII d. C.

${ }^{15}$ ECKHART, M. Op. cit. p. 170ss, 1983.
} 
na relação dialética entre Marta e Maria, mas se funda nos propósitos místicos da ação de Marta. No trecho acima, há uma aplicação ética do seu argumento, uma vez que Eckhart distingue os que estão juntos de Deus, os que estão junto com as coisas e os que estão nas coisas. É possível, estar nas coisas e junto com Deus, mas não é possível estar junto das coisas e junto de Deus. Está no fundo deste argumento toda a concepção de desapego para a perfeita união com Deus. Nesse sentido, Eckhart não rompe com o plano dogmático do magistério, tampouco é literal em sua abordagem, antes, seguindo o método anagógico, insere uma rica contribuição à interpretação do texto, passando-o ao critério do conceito de unio.

\section{Conclusão}

Procuramos neste breve artigo, destacar algumas das principais lentes hermenêuticas usadas por Meister Eckhart, particularmente em seus Sermões, comumentemente conhecidos como Sermões Alemães. A Teologia Ascética deve ser compreendida não como um subjetivismo fundado em experiências de êxtase, mas como uma lente hermenêutica a priori enriquecida com a criatividade teológica comum dos(as) místicos(as). Fazer Teologia Ascética, é antes de mais nada, estar disposto a transcender os limites tradicionais da Teologia e transitar por outras formas de pensar e conceber a realidade divina. Eckhart, como grande biblista, não irá prescindir destas lentes para sua obra. Infelizmente Eckhart não foi entendido e as disputas teológicas de seu tempo entre dominicanos e franciscanos acabaram por excluir sua contribuição teológica para o ocidente por longos séculos. Os poucos mais de noventa sermões da coleção Sermões Alemães, com certeza são uma pequena contribuição de seu pensamento que chegou a nós. Algumas outras obras importantes que revelam sua compreensão teológica também foram conservadas, entretanto é possível que muito tenha se perdido, por conta da sentença papal de heresia impetrada um ano após sua morte. Outro aspecto importante é que sua obra foi basicamente composta para atender a necessidades pastorais, especialmente dos conventos que estavam subordinados a sua liderança quanto à formação dos sacerdotes os quais foram seus discípulos enquanto professor em Paris e Colônia. Eckhart longe de ser um teólogo apenas acadêmico, divide harmoniosamente sua vida com equilíbrio entre academia e pastoral. 


\section{Referências}

ECKHART, Mestre. A mística de ser e de não ter. Coord. Leonardo Boff. Petrópolis: Vozes, 1983. (Série Espiritualidade, 5). 1991. . O Livro da Divina Consolação e outros textos seletos. 2. ed. Petrópolis: Vozes, . Sobre o desprendimento e outros textos. Trad. do Médio-Alemão de Alfred J. Keller. São Paulo: Martins Fontes, 2004.

. Sermões Alemães 1. Bragança Paulista/Petrópolis: Ed. Universitária São Francisco/Vozes, 2006. Vol. 1 e 2.

Três Iniciados. O Caibalion. São Paulo: Pensamento. 1978.

UNDERHILL, Evelyn. Mysticism - A study in the nature and development of Man's spiritual consciousness. New York: Meridian Books, 1958.

ZĂK, Lubomir. Trindade e imagem - Aspectos da teologia mística de Vladimir Losskij. Márcio Luiz Fernandes (Org.). São Paulo: Ave-Maria, 2012.

Recebido: 17/09/2014

Avaliado: 05/10/2014 